\title{
Outcome of oesophagogastric carcinoma in young patients
}

\author{
D J Bowrey, G W B Clark, B I Rees, G T Williams, P D Carey
}

\section{Summary}

The survival of young patients $(\leqslant 50$ years of age) with carcinoma of the oesophagus or stomach has been reported to be poorer than that of their older counterparts. The aim of the current study was to review the outcome of such young patients with oesophagogastric cancer and to compare the outcome in patients with carcinoma of the oesophagus/cardia with patients with carcinoma of the more distal stomach. The study population was 50 patients. Tumour location was oesophagus/cardia $(n=33)$ and gastric bodylantrum $(n=17)$. The most common presenting symptoms were weight loss $(66 \%)$, epigastric pain (54\%), dysphagia (50\%), and heartburn $(40 \%)$. Seventeen patients had experienced foregut symptoms for a period of $\geqslant 6$ months. These patients were more likely to have symptoms of gastro-oesophageal reflux disease and to have received acid suppression therapy than patients with shorter symptom durations. Only 20 patients underwent a potentially curative resection, while 10 underwent open and close laparotomy. The overall median survival was 7 months and the 5-year survival was $8 \%$. Multivariate analysis revealed that surgical resection and UICC stage were the only factors that significantly influenced survival. There was no difference in the survival of patients with proximally situated tumours compared to those with distally located tumours. Wide variations in clinical practice were seen between different surgeons. Consequently, a multidisciplinary team designed to manage all patients with oesophagogastric cancer according to nationally agreed protocols has been established in our hospital. Earlier diagnosis of these tumours is to be encouraged, even if this necessitates the more liberal use of endoscopy in the evaluation of young patients with persistent foregut symptoms.

Keywords: oesophagus; stomach; carcinoma; surgery; age-factors

In recent years, the incidence of adenocarcinoma of the oesophagus and cardia has increased in the Western hemisphere. ${ }^{12}$ Approximately $5 \%$ of patients with these cancers are aged 50 years or younger. ${ }^{3}$ Thus, the absolute number of young patients with oesoph- agogastric carcinoma can be expected to increase. It has been reported that the survival of young patients with these tumours is poorer than that of their older counterparts, ${ }^{4-11}$ possibly because they have a more biologically aggressive disease.

The purpose of this study was to review the outcome of young patients (aged 50 years or less) with carcinoma of the oesophagus or stomach. Similarly, we wished to compare the outcome for patients with cancers of the oesophagus and cardia to the outcome for patients with carcinoma of the more distal stomach.

\section{Patients and methods}

The study population consisted of all patients aged 50 years or less at the time of diagnosis of carcinoma of the oesophagus or stomach at hospitals in the former region of South Glamorgan Heath Authority, Wales, UK (now Bro-Taf Health Authority) during the period 1989-96. These comprised a University teaching hospital, two affiliated district general hospitals, and the regional oncology centre. Patients were identified from the Hospital Patient Episode Database which is a computerised registry of all hospital attendances that lists patient age and diagnosis according to the diagnostic coding of the International Classification of Diseases (ICD). During the first part of the study period classification was according to ICD-9 and during the remainder ICD-10. The case notes of those patients with the ICD-9 codes 150.1 to 151.9 , and ICD-10 codes C15.1 to C16.9 were reviewed retrospectively. The following information was extracted: age, gender, presenting features, radiological imaging, endoscopy findings, surgical treatment and complications. Tumour location was determined from either the surgical resection specimen or from the endoscopy report. Outcome data for all patients was obtained from the Bro-Taf Death Registration Department.

Clinicopathologic staging was according to the American Joint Committee on Cancer/ International Union Against Cancer (AJCC/ UICC) classifications ${ }^{12}{ }^{13}$ which utilise the TNM classification of oesophageal and gastric cancer (table 1). The TNM staging for both cancers are similar, with the $\mathrm{T}$ and $\mathrm{M}$ stages being identical. However, the $\mathrm{N}$ stage differs in that oesophageal carcinoma is classified simply as N0 (lymph node metastases absent) or N1 (lymph node metastases present), whilst for 
Table 1 AJCC/UICC classification of oesophagogastric cancer ${ }^{12} 13$

\begin{tabular}{lll}
\hline & Gastric cancer & Oesophageal cancer \\
\hline Stage I & T1-2 N0 M0 or T1 N1 M0 & T1 N0 M0 \\
Stage II & T1 N2 M0 or T2 N1 M0 or T3 N0 M0 & T2-3 N0 M0 or T1-2 N1 M0 \\
Stage III & T2 N2 M0 or T3 N1-2 M0 or T4 N0-1 M0 & T3 N1 M0 or T4 Any N M0 \\
Stage IV & T4 N2 M0 or Any T Any N M1 & Any T Any N M1 \\
\hline
\end{tabular}

Table 2 Patient characteristics according to tumour location

\begin{tabular}{llll}
\hline & $\begin{array}{l}\text { Oesophagus } \\
(n=17)\end{array}$ & $\begin{array}{l}\text { Cardia } \\
(n=16)\end{array}$ & $\begin{array}{l}\text { Stomach } \\
(n=17)\end{array}$ \\
\hline Male:female & $15: 2$ & $15: 1$ & $8: 9^{\star}$ \\
Weight loss & $10(59 \%)$ & $13(81 \%)$ & $10(59 \%)$ \\
Dysphagia & $13(76 \%)$ & $9(56 \%)$ & $3(17 \%)^{\star \star}$ \\
Epigastric pain & $5(29 \%)$ & $9(56 \%)$ & $13(76 \%)^{\star \star \star}$ \\
Heartburn & $10(59 \%)$ & $6(37 \%)$ & $4(24 \%)$ \\
Symptom duration $\geqslant 6$ months & $5(29 \%)$ & $6(37 \%)$ & $6(35 \%)$ \\
Acid suppression therapy $>1$ month & $6(35 \%)$ & $4(25 \%)$ & $7(41 \%)$ \\
Poorly differentiated tumour & $8(47 \%)$ & $9(56 \%)$ & $13(76 \%)$ \\
\hline
\end{tabular}

${ }^{\star} \chi^{2}=12.0, \mathrm{p}<0.01 ;{ }^{\star \star} \chi^{2}=12.1, \mathrm{p}<0.01 ;{ }^{\star \star \star} \chi^{2}=7.6, \mathrm{p}<0.05$.

gastric carcinoma, two node positive categories are specified. N1 defines lymph node metastases within $3 \mathrm{~cm}$ of the primary tumour whilst $\mathrm{N} 2$ defines lymph node metastases more than 3 $\mathrm{cm}$ from the primary tumour or the involvement of nodes along the left gastric, common hepatic, splenic or coeliac arteries. Patients undergoing surgery were staged by histological examination of the resected specimen or, in cases where resection was not undertaken, from the operative findings. In those patients who did not undergo surgery, staging was based upon computed tomography findings or upon abdominal ultrasonography. For the majority of these patients, M1 disease was identified by the presence of hepatic metastases or ascites.

Statistical analysis was performed by the chisquare test and Fisher's exact test for comparison of proportions, and the Mann-Whitney U-test for comparison of non-parametric data. Survival was estimated by the Kaplan-Meier method with univariate analysis by the log-rank test and multi-variate comparison by Cox's

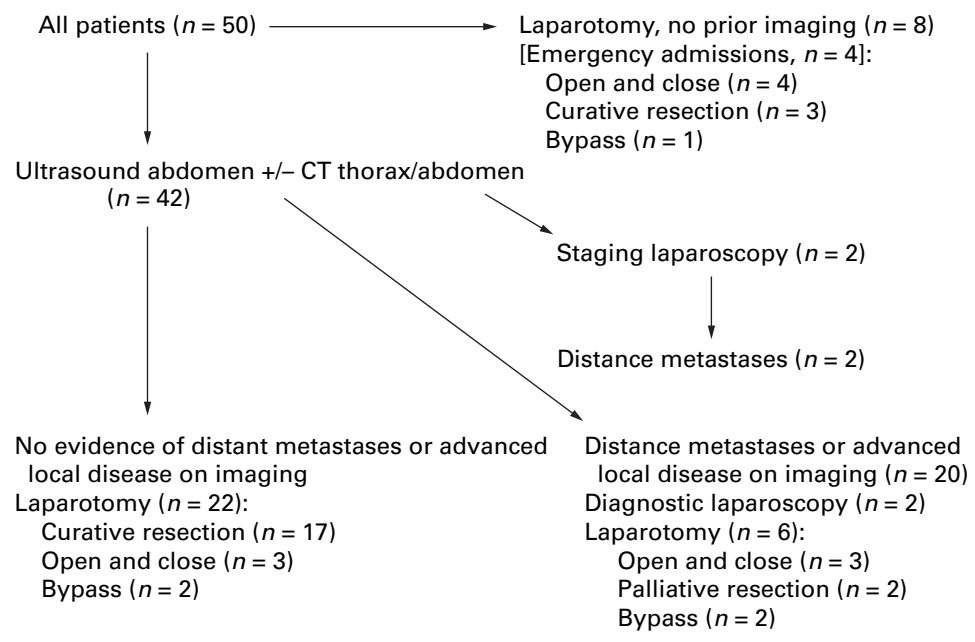

Figure 1 Schedule of patient management proportional hazards model using forward variable selection. Significance was taken at the $5 \%$ level.

\section{Results}

STUDY POPULATION

Between 1 January 1989 and 31 December 1996, 901 patients were diagnosed with carcinoma of the oesophagus or stomach, 55 of whom $(6 \%)$ were aged 50 years or less at the time of diagnosis. Complete data were available for 50 patients ( 38 men, 12 women) of median age 44 years (range $28-50$ ). Primary tumour by site was as follows: oesophagus and gastric cardia: 33 patients (66\%); gastric body and antrum: 17 patients $(34 \%)$. Six patients with oesophageal cancer and one patient with carcinoma of the cardia had squamous cell carcinoma, while the remaining patients had adenocarcinoma. Thirty patients $(60 \%)$ had poorly differentiated tumours (table 2 ).

\section{PATIENT CHARACTERISTICS}

The commonest presenting symptoms were weight loss $(n=33,66 \%)$, epigastric pain $(n=27$, $54 \%)$, dysphagia $(n=25,50 \%)$ and heartburn $(n=20,40 \%)$. The median duration of symptoms at presentation was 3 months (interquartile range 2-16 months). Seventeen patients $(34 \%)$ had experienced foregut symptoms for a period of 6 months or more. These 17 patients had a median symptom duration of 30 months (9-162); none had undergone gastroscopy in the 12 months preceding diagnosis. Two patients were known to have Barrett's oesophagus, neither were in a surveillance programme. Seventeen patients (34\%) had received acid suppression therapy, either H2-receptor blockers or proton-pump inhibitors, in the months preceding diagnosis (table 2).

Patients with symptoms of gastrooesophageal reflux disease (heartburn or regurgitation) were symptomatic for significantly longer than those free of these symptoms (14 months (3-168) vs 3 months $(2-5), \mathrm{p}<0.05)$. Further, patients that had received acid suppression therapy were symptomatic for significantly longer than patients not receiving these medications (10.0 months (3.0-180.0) vs 3.0 months (2.0-6.7), p<0.05).

PRE-OPERATIVE IMAGING

Figure 1 shows the imaging which was performed pre-operatively and its relationship to the surgery performed.

SURGERY

The patients were treated by a total of 10 surgeons, most of whom would not consider themselves to be specialist upper gastrointestinal surgeons. Overall, only 20 patients $(40 \%)$ underwent a potentially curative resection (table 3). Ten patients with oesophageal carcinoma underwent resection ( $8 \mathrm{R} 0,2 \mathrm{R} 1)$ as follows: Ivor-Lewis procedure $(n=4)$, left thoraco-abdominal resection $(n=4)$ and threestage oesophagectomy $(n=2)$. Six patients with cardia carcinoma underwent left thoraco- 
Table 3 Patient treatment according to tumour location

\begin{tabular}{lrll}
\hline & $\begin{array}{l}\text { Oesophagus } \\
(n=17)\end{array}$ & $\begin{array}{l}\text { Cardia } \\
(n=16)\end{array}$ & $\begin{array}{l}\text { Stomach } \\
(n=17)\end{array}$ \\
\hline R0/R1 resection & 10 & 5 & 5 \\
R2 resection or bypass procedure & 0 & 3 & 3 \\
Exploratory surgery. No resection & 2 & 2 & 6 \\
No operation & 5 & 6 & 3 \\
\hline
\end{tabular}

Table 4 Clinicopathologic stage according to tumour location

\begin{tabular}{lcr}
\hline & $\begin{array}{l}\text { Oesophagus E cardia } \\
(n=33)\end{array}$ & $\begin{array}{l}\text { Stomach } \\
(n=17)\end{array}$ \\
\hline Stages I \& II & $8(24 \%)$ & $3(18 \%)$ \\
Stage III & $11(33 \%)$ & $4(24 \%)$ \\
Stage IV & $14(42 \%)$ & $10(59 \%)$ \\
\hline
\end{tabular}

abdominal resection (4 R0, $1 \mathrm{R} 1,1 \mathrm{R} 2$ ). Six patients with gastric carcinoma underwent resection (4 R0, 1 R1, $1 \mathrm{R} 2$ ) as follows: Billroth I $(n=1)$, Billroth II $(n=4)$ and total gastrectomy $(n=1)$. D2 lymphadenectomy was employed in only one patient in this series. Overall, 10/50 patients (20\%) underwent an exploratory laparotomy without any surgical procedure being performed, seven of whom had peritoneal metastases and three had extensive local nodal disease. Of these 10 patients, four had not had any prior imaging of their tumour. Patients who were staged pre-operatively were less likely to undergo exploratory surgery without resection than patients who had no pre-operative staging ( $14 \%$ vs $50 \%, \mathrm{p}<0.05$, Fisher's exact test).

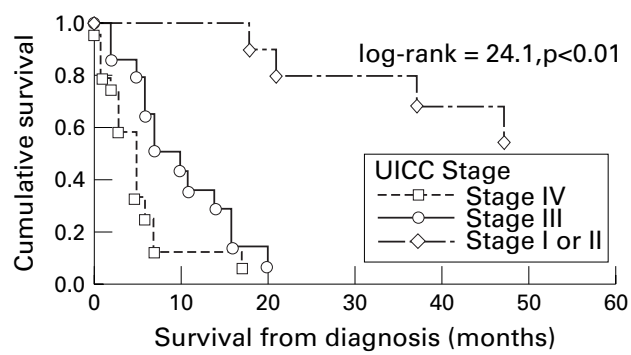

Figure 2 Survival by UICC stage. Stage I\&II vs III log-rank $=16.4, \mathrm{p}<0.01$; stage I\&II $v s$ IV log-rank=17.9, $\mathrm{p}<0.01$; stage III $v$ IV $\log$-rank $=4.1, \mathrm{p}<0.05$

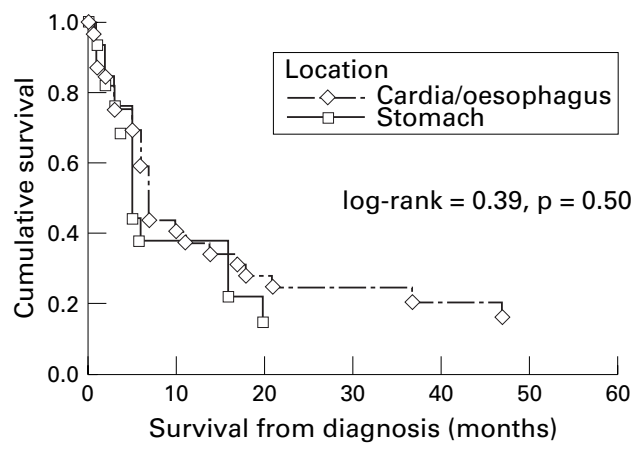

Figure 3 Survival by tumour location
STAGING

There was no significant difference between patients with carcinoma of the cardia/ oesophagus and patients with carcinoma of the more distal stomach with respect to clinicopathologic stage (table 4). The duration of symptoms at the time of presentation showed no correlation with clinicopathologic stage, ie, patients who had been symptomatic for longer time periods were not more likely to have more advanced disease.

\section{RADIOCHEMOTHERAPY}

Six patients with carcinoma of the oesophagus and five patients with carcinoma of the cardia received pre-operative chemotherapy with epirubicin, cisplatin and 5-fluorouracil. Three of these patients also received pre-operative radiotherapy. Twelve patients received postoperative chemotherapy with regimens that included the agents epirubicin, cisplatin, 5-fluorouracil and mitomycin.

SURVIVAL

The overall median survival was 7 months (5.0-20.0) and the overall 1-year, 2-year and 5 -year survivals were $34 \%, 20 \%$ and $8 \%$, respectively. The influence of the following factors on patient survival was investigated: degree of tumour differentiation, histologic type (squamous cell carcinoma vs adenocarcinoma), administration of pre-operative or post-operative radiochemotherapy, surgical resection, gender, UICC stage, symptom duration, tumour location (cardia and oesophagus $v s$ stomach) and prior use of acid suppression therapy. Univariate and multivariate analysis revealed that only surgical resection $(p<0.05)$ and UICC stage $(p<0.05)$ significantly influenced survival. Figure 2 shows patient survival according to UICC stage. The median survival of patients with stage III disease was 10.0 months 5.2-14.8) and for stage IV disease, it was 5.0 months (3.5-6.5). Patients with stage I and II disease had not reached their median survival at a median follow-up time of 37 months (21-89) with $7 / 11$ patients alive. For these young patients, there was no significant difference in survival between patients with carcinoma of the cardia/oesophagus and patients with carcinoma of the gastric body/ antrum, 7.0 months (5.9-8.1) vs 5.0 months (3.5-6.5), see figure 3.

\section{Discussion}

The high frequency of tumours occurring at the gastro-oesophageal junction and the high male:female ratio are in keeping with publications from other investigators reporting on patients of all ages. ${ }^{12}$ Blot et al stated that, for the time period 1976-87, the rate of increase in incidence of adenocarcinoma of the oesophagus and gastric cardia had "surpassed that of any other cancer, outpacing increases in the incidence of skin melanoma, non-Hodgkin's lymphoma, and cancers of the lung".

One of the principal study findings was that survival of young patients with oesophageal or gastric carcinoma was highly dependent upon 
Table 5 Literature review of oesophagogastric carcinoma in young patients

\begin{tabular}{|c|c|c|c|c|c|c|c|}
\hline Reference & Time period & Country & $\begin{array}{l}\text { Patient } \\
\text { age } \\
\text { (years) }\end{array}$ & $\begin{array}{l}\text { Patients } \\
\text { (n) }\end{array}$ & $M / F$ ratio & $\begin{array}{l}\text { 5-yr } \\
\text { survival } \\
(\%)\end{array}$ & $\begin{array}{l}\text { Unselected } \\
\text { or surgical } \\
\text { bias }\end{array}$ \\
\hline \multicolumn{8}{|c|}{ Carcinoma stomach } \\
\hline 15 & $1944-74$ & US & $<40$ & 73 & 0.92 & 20 & Unselected \\
\hline 16 & $1946-76$ & US & $\leqslant 35$ & 37 & 0.4 & 5 & Unselected \\
\hline 11 & 1970-79 & Canada & $\leqslant 40$ & 31 & 1.24 & 22 & Unselected \\
\hline 17 & $1948-83$ & US & $\leqslant 35$ & 38 & 1.0 & 3 & Unselected \\
\hline 18 & $1980-85$ & $\begin{array}{l}\text { South } \\
\text { Africa }\end{array}$ & $\leqslant 35$ & 37 & 0.95 & 3 & Unselected \\
\hline 5 & $1965-85$ & Japan & $<30$ & 38 & 0.9 & 33 & Surgical \\
\hline 10 & $1965-83$ & Japan & $<50$ & $\begin{array}{l}140 \mathrm{M} \\
122 \mathrm{~F}\end{array}$ & 1.1 & $\begin{array}{l}45 \\
32\end{array}$ & Surgical \\
\hline \multicolumn{8}{|c|}{ Carcinoma oesophagus } \\
\hline 19 & $1965-88$ & Japan & $<50$ & 28 & 6.1 & 9.5 & Surgical \\
\hline 9 & $1980-89$ & India & $<50$ & $\begin{array}{l}87 \mathrm{M} \\
69 \mathrm{~F}\end{array}$ & 1.3 & $\begin{array}{l}16 \\
35\end{array}$ & Surgical \\
\hline 6 & $1968-78$ & China & $\leqslant 35$ & 76 & 3.2 & 27 & Surgical \\
\hline 20 & 1983-92 & UK & $<50$ & 47 & 1.8 & 16 & Surgical \\
\hline \multicolumn{8}{|c|}{ Carcinoma oesophagus E stomach } \\
\hline Current series & 1989-96 & UK & $\leqslant 50$ & 50 & 3.2 & 8 & Unselected \\
\hline
\end{tabular}

the clinicopathologic stage at presentation. Tumour stage and the performance of surgical resection were the only two factors that correlated with survival on multivariate analysis. Patients with stages I and II disease had yet to attain their median survival at a follow-up time of 37 months. This underscores the importance of an early diagnosis for these patients. In an attempt to promote the earlier diagnosis of upper gastrointestinal cancer, open access gastroscopy ${ }^{14}$ has been introduced into the UK. However, many units, including our own, impose age guidelines on the provision of open access gastroscopy to general practitioners, targeting specifically those over the age of 45 years. Thirty-two of the study patients $(64 \%)$ were aged 45 years or less. Of concern, $17(34 \%)$ of these young patients had experienced foregut symptoms for long periods of time at the time of diagnosis. In particular, the symptoms of gastro-oesophageal reflux disease were associated with significantly longer symptom durations at the time of diagnosis.

Review of the literature (table 5) reveals that the overall 5-year survival of $8 \%$ is in keeping with that reported by other investigators describing unselected series. ${ }^{11}{ }^{15-18}$ Higher survivals were published by centres reporting only surgical patients. ${ }^{59101920}$

1 Powell J, McConkey CC. Increasing incidence of adenocarcinoma of the gastric cardia and adjacent sites. $\mathrm{Br} F$ Cancer 1990;62:440-3.

2 Blot WJ, Devesa SS, Kneller RW, Fraumeni JF. Rising incidence of adenocarcinoma of the esophagus and gastric cardia. FAMA 1991;265:1287-9.

3 Office for National Statistics (formerly Office of Population Censuses and Surveys). Cancer Statistics Registrations 1970 1990. London: Office for National Statistics, 1990.

4 Mitsudomi T, Matsusaka T, Wakasugi $\mathrm{K}$, et al. A clinicopathological study of gastric cancer with special reference to age of the patients: an analysis of 1630 cases. World f Surg 1989;13:225-31.

5 Maehara Y, Orita H, Moriguchi S, Emi Y, Haraguchi M, Sugimachi K. Lower survival rate for patients under 30 years of age and surgically treated for gastric carcinoma. $\mathrm{Br}$ f Cancer 1991;63:1015-7.

$6 \mathrm{Lu} \mathrm{JP}$, Xian MS, Hayashi K. Morphologic features in esophageal squamous cell carcinoma of young adults in North China. Cancer 1994;74:573-7.

7 Esaki Y, Hirayama R, Hirokawa K. A comparison of patterns of metastasis in gastric cancer by histologic type and age. Cancer 1990;65:2086-90.
This paper highlights several management issues. Firstly, some 10 surgeons were involved in the care of these patients, most of whom would not consider themselves specialist upper gastrointestinal surgeons. Further, $20 \%$ of patients underwent exploratory laparotomy, at which no resection was performed. This was a particular problem in patients who had not been staged pre-operatively. The high exploratory laparotomy rate in these young patients could be justified by the surgeons' intentions to do everything possible for the patient and their family. However, clearly open and close laparotomies do the patient no service.

One way forward under these circumstances is the establishment of a Calman style cancer unit $^{21}$ for the treatment of these patients. In our own region we have established a multidisciplinary team ${ }^{22}$ to manage all patients with oesophagogastric cancer. Since 1996 all patients with foregut cancers have been managed according to locally agreed protocols based on best clinical practice ${ }^{24}$ in an attempt to optimise patient management.

In conclusion, up to a third of young patients with oesophagogastric cancer were symptomatic for long periods of time before a diagnosis was reached; this was especially so for those with a history of gastro-oesophageal reflux disease. In young patients there was a high frequency of cancers affecting the oesophagus and gastro-oesophageal junction, similar to the trend observed in older patients. Survival was highly correlated with clinicopathologic stage and the performance of a complete surgical resection. Earlier diagnosis of these tumours is to be encouraged even if this necessitates the more liberal use of endoscopic evaluation of young patients with persistent foregut symptoms. Management of young patients with oesophageal or gastric cancer should be according to established protocols in order to improve outcomes and avoid inappropriate exploratory surgery.

Mr David Bowrey was salaried in part by a Royal College of Surgeons of England / Welsh Office grant. The authors are grateful to Dr Frank Dunstan, Senior Lecturer in Medical Statistics for his advice.

8 Moriguchi S, Korenaga D, Sugimachi K, Nose Y. Relationship between age and the time of surgery and prognosis after gastrectomy for gastric cancer. F Surg Oncol 1993;52:11923.

9 Badwe RA, Patil PK, Bhansali MS, Mistry RC, Juvekar RR, Desai PB. Impact of age and sex on survival after curative resection for carcinoma of the esophagus. Cancer 1994;74: $2425-9$

10 Maehara Y, Watanabe A, Kakeji Y, et al. Prognosis for surgically treated gastric cancer patients is poorer for women than men in all patients under age 50. Br F Cancer 1992;65: $417-20$.

11 Grabiec J, Owen DA. Carcinoma of the stomach in young persons. Cancer 1985;56:388-96.

12 American Joint Committee on Cancer: Stomach cancer. In: Beahrs OH, Henson DE, Hutter RVP, Kennedy BJ, eds, Manual for staging cancer, 4 th edn. Philadelphia: JB Lippincott, 1992.

13 American Joint Committee on Cancer: Esophageal cancer. In: Beahrs OH, Henson DE, Hutter RVP, Kennedy BJ, eds, Manual for staging cancer, 4 th edn. Philadelphia: JB Lippincott, 1992 .

14 Silcock JG, Bramble MG. Open access gastroscopy: second survey of current practice in the United Kingdom. Gut 1997;40:192-5. 
15 Bedikian AY, Khankhanian N, Heilbrun LK, Bodey GP, Stroehlein JR, Valdivieso M. Gastric carcinoma in young Stroehlein JR, Valdivieso M. Gastric
adults. South Med $\mathcal{1}$ 1979;72:654-6.

16 Bloss RA, Miller TA, Copeland EM. Carcinoma of the stomach in the young adult. Surg Gynecol Obstet 1980;150: 883-6.

17 Tso PL, Bringaze WL, Dauterive AH, Correa P, Cohn Jr I. Gastric carcinoma in the young. Cancer 1987;59:1362-5.

18 Matley PJ, Dent DM, Madden MV, Price SK. Gastric carcinoma in young adults. Ann Surg 1988;208:593-6.

19 Mori M, Ohno S, Tsutsui S, Matsuura H, Kuwano H, Sugimachi K. Esophageal carcinoma in young patients. Ann Thorac Surg 1990;49:284-6.

20 Adam DJ, Craig SR, Sang CTM, Walker WS, Cameron EWJ. Oesophagogastrectomy for carcinoma in patients under 50 years of age. $\mathcal{F} R$ Coll Surg Edinb 1996;41:371-3.
21 Expert Advisory Group on Cancer to the Chief Medical Officer of England and Wales. A Policy Framework for Commissioning Cancer Services. London: Department of Health, 1994.

22 Clark GWB, Jefferson $\mathrm{M}$, Hawthorne $\mathrm{AB}$, et al. A multi-disciplinary approach to the management of oesophago-gastric carcinoma: the early experience (Abstract). Br f Surg 1998;85:413.

23 Clark GWB, Roy MK, Corcoran B, Carey PD. Carcinoma of the oesophagus: time for a multi-disciplinary approach ? Surg Oncol 1997;5:149-64.

24 Cancer Services Expert Group. Cancer Services in Wales. A Report by the Cancer Services Expert Group, vol 2. Welsh Office, 1996; pp 143-76. 